\title{
BIBLIOTECAS DE LOGROÑESES DEL S. XVIII
}

\author{
Equipo RUBRUM'
}

\section{Los escasos mimbres del cesto}

Los partidarios de que en España la llustración dieciochesca fue un fenómeno de tono menor que contagió sólo a una parte de la elite $y$, además, "benignamente ${ }^{\prime 2}$, verán en la veintena de bibliotecas de particulares logroñeses que hemos estudiado a través de inventarios de bienes un ejemplo más de los muchos que pueden apoyar empíricamente sus tesis. Para los más extremistas, incluso este tipo de estudios sobre libros y librerías carecería de entidad pues no demuestra más que lo obvio, lo ya conocido: hay pocos libros, pertenecen a los profesionales ricos y al clero, y entre las obras predominan las de devoción, los clásicos, las de escritores españoles -Cervantes, Quevedo, como mucho Feijoo, etc.- y las relativas a la profesión. El cauta lege, la omnipresen-

1. El equipo Rubrum, dirigido por José Luis GÓMEZ URDÁÑEZ, catedrático de Historia Moderna de la Universidad de La Rioja, con la colaboración de Diego TÉLLEZ ALARCIA, becario F.P.I. de la misma, está compuesto por estudiantes de $4^{\circ}$ curso de Humanidades, alumnos de la asignatura Historia del libro y de la difusión de la Cultura que han desarrollado las clases prácticas en el Archivo Histórico Provincial de Logroño, buscando bibliotecas en los inventarios post mortem de los protocolos notariales, y luego redactando en grupo el artículo que sigue. Sus nombres son: Charo ARMENDÁRIZ, David BENI, Carolina BURGOS, Sonia CENICEROS, Leticia EGUIZABAL, Catalina FAJARDO, Myriam FERREIRA, Pepe GÓMEZ LOZANO, Beatriz GÓMEZ TOBÍA, Fernando GUTIÉRREZ, Beatriz INZA, J. Manuel MADURGA, José María MARQUÉS, Ana NOVOA, Pedro M. PASTOR, Lorena PÉREZ, Rosa Ma PINILLOS, Sandra RODRÍGUEZ, Julia ROLDÁN.

2. Las bibliotecas de los ilustrados españoles dan evidentes muestras de ellos. Véanse las de Ensenada, Campomanes, Jovellanos u Ordeñana: GÓMEZ URDÁÑEZ, J. L., El proyecto reformista de Ensenada. Lérida, 1996, pp. 263-299; SOUBEYROUX, J., La Biblioteca de Campomanes: contexto cultural de un ilustrado. Roma, 1982; AGUILAR PIÑAL, F., La biblioteca de Jovellanos (1778). Madrid, 1994 y GONZÁLEZ CAIZÁN, C., "La biblioteca de Agustín Pablo de Ordeñana". Brocar 21 (1997), pp. 227-268. 
te censura ${ }^{3}$, la pervivencia de una mentalidad inquisitorial, todo ello junto a la carestía de los libros y la restricción de su comercio, vendría a justificar las tesis de una llustración corta y, desde luego, poco difundida librescamente ${ }^{4}$.

Después del breve paseo por las bibliotecas de los logroñeses dieciochescos nuestras conclusiones han de abonar, en efecto, las tesis anteriores. La vieja ciudad castellana no podía ser un escenario de innovación cultural; pero es que incluso, a juzgar por la cortedad de las bibliotecas, no era tampoco un reservorio de la cultura libresca tradicional "acumulada" de tiempos anteriores. Es evidente que la Ilustración, -en general la cultura española de la Edad Modernano fue un fenómeno de masas, ni desde luego pudo abrirse paso cómodamente en una pequeña ciudad, ruralizada y superpoblada de clérigos, sede de un famoso tribunal de la Inquisición y yerma de instituciones dedicadas a la docencia superior. Logroño, ciudad rural, agraria y vinatera, no gozó de las mejores condiciones -éstas son las que tuvo la burguesía de las ciudades portuarias como Cádiz, Valencia, Barcelona, y sobre todo la corte-, pero relativamente, no estaba tan mal en cuanto a la tasa de alfabetización y contaba con una imprenta que, aunque no era sombra de lo que fue, al menos existía, lo que sólo podían decir menos de treinta ciudades españolas a mediados de siglo ${ }^{5}$.

A la luz de los estudios de Jacques Soubeyroux y M. H. Buisine, Logroño presenta para el XVIII una tasa de alfabetización media-alta en comparación con las ciudades de las que disponemos de estudios. Por ejemplo, Logroño tenía menos analfabetos que la cercana Burgos o que Madrid, y menos analfabetas que ciudades como Burgos, Zamora, Ávila, Palencia, Madrid o Murcia ${ }^{6}$. En cuanto a los medios de alfabetización, sobre todo en lo que concierne al principal, la escuela, Logroño presentaba también una buena situación relativa. Según el Catastro de Ensenada, los jesuitas mantenían en su colegio dos maestros de primeras letras y dos de gramática; además, cuatro vecinos de Logroño ejercían la profesión de maestro de primeras letras, mientras al menos dos mujeres se ocupaban de la enseñanza de niñas. Bien es cierto que ellas mismas declaran que les enseñan a "a hacer media y leer" en un caso, en otro caso a

3. Sobre la censura y la inquisición en la difusión de libros: DEFOURNEAUX, M., Inquisición y censura de libros en la España del s. XVIII. Madrid, 1973.

4. El estudio de librerías y difusión de libros ha cobrado un enorme interés en España en los últimos años. Tras los estudios pioneros de J.E. Gelabert, L.C. Alvarez Santaló, F. Lopez, L. Domergue, A. Risco, prosigue la investigación y los frutos. Son de señalar los trabajos de A. Viñao Frago, C. Mas Galván y especialmente los de O. Rey Castelao.

5. Veintisiete da el inventario en tiempos de Curiel, mediados del XVIII, cfr. LÓPEZ, F., "Un apercu de la librairie espagnole au milieu du XVIIIe siècle", en De l'alphabetisation aux circuits du livre en Espagne, XVle-XIXe siècles. París, 1987, p. 387 y ss.

6. Cfr. BUISINE, M. H. y SOUBEYROUX, J., "La Realidad Social: el dominio del alfabetismo" en GÓMEZ URDÁÑEZ, J.L. (Coord.), Historia de la ciudad de Logroño. Logroño, 1995, Tomo IV, p. 127, cuadro 2. 
"coser y tañer el arpa". Por último el organista de la Colegial declaraba dar clase a "señoritas", obviamente de música".

Aunque no conocemos de manera pormenorizada la situación de las profesiones liberales más relacionadas con la cultura y el mundo de los universitarios logroñeses, lo que conocemos presenta también un buen panorama. En 1752 había en la ciudad 36 jóvenes de 14 a 27 años que estudiaban en diferentes universidades. Es cierto que la práctica totalidad pertenecían a la elite urbana que "usaba" la universidad para sus estrategias de mantenimiento del status -aunque hay un caso de un estudiante logroñés, hijo de un albañil, que tenía que mantenerse de limosnas para estudiar- y que, en definitiva, muchos acabarían ejerciendo la clerecía. Pero, quizás, como concluye J. Soubeyroux, haya un interés por la universidad en Logroño superior al que muestran, por ejemplo, los leoneses "cuyos hijos se quedaban en la provincia contentándose con estudiar Gramática o Artes en León o Astorga"8. Todo ello sumado a una situación económica más bonancible que la del mundo agrario castellano gracias a la exportación de vinos ${ }^{9}$, permite que el poblachón riojano parezca una ciudad atractiva para servicios más o menos relacionados con un nivel de cultura y de formación profesional, que es lo único que permite encontrar alguna biblioteca con libros, digamos... interesantes.

Con unos 6.500 habitantes, Logroño es una ciudad bien servida por diferentes profesionales, como médicos (4), cirujanos (17), boticarios (3), abogados (12), escribanos (9) y procuradores (5). De todas formas, lo que más abunda en la ciudad son los curas (no menos de 444), una profesión en la que hemos de reparar por su influencia en la educación y, sin duda, en la elevación de la tasa de alfabetización. Cabría suponer que una ciudad con tan alto número de clérigos, a los que se supone "consumidores" de libros, y con un elenco de profesiones liberales bien cubierto, nos ofrecería inventarios de bibliotecas bien surtidas y en un número elevado. Sin embargo, no es el caso.

A pesar de que uno de cada cuatro logroñeses varones adultos es cura, los escribanos inventariaron pocas bibliotecas de clérigos. Puede deberse a que nuestra cata no es lo suficientemente representativa, pero también a otros factores: a la propia naturaleza del inventario post mortem, menos utilizado en el caso de los clérigos que en el de los no célibes -a causa de las particiones entre hijos y segundos matrimonios, causa frecuente de los inventarios-, al poco

7. Archivo Histórico Provincial de Logroño (en adelante A.H.P. Lo.), Sección Catastro, Logroño, respuestas generales. Hay una síntesis de las respuestas en ALONSO CASTROVIEJO, J. J., Logroño 1751: según las respuestas generales del Catastro de Ensenada. Madrid, 1990. Sobre el magisterio a través del Catastro, véase LABRADOR, C., La escuela en el Catastro. Madrid, 1988.

8. BUISINE, M. H. y SOUBEYROUX, J., "La Realidad Social...", p. 140.

9. Sobre la importancia del viñedo, véase GÓMEZ URDÁÑEZ, J.L. (dir.), El Rioja histórico: La Denominación de Origen y su Consejo Regulador. Logroño, 2000. 
valor que se concede al libro e incluso a la ocultación, aunque esto sea menos usual en el caso de los clérigos que entre los ricos, en cuyos inventarios el notario puede no creer conveniente anotar listas de libros de valor incierto o difícilmente transformable en dinero ${ }^{10}$.

En cualquier caso, el clero riojano tenía ganada fama de inculto. Es conocida la reflexión de Feijoo en sus Cartas Eruditas sobre la poca formación del clero de la diócesis de Calahorra, y cada vez se va sabiendo más de las peculiaridades de un distrito que englobaba las Provincias Vascongadas y que mantenía en la ciudad del Ebro un notable exceso de clérigos expectantes de destino ${ }^{11}$. Jovellanos, que fue muy crítico con lo que vio en la ciudad, dejó escrito en sus diarios: "las causas de su miseria, Convento de la Trinidad, a un tiro de bala de a Inquisición, Convento de Mercedarios. Tiene además, Dominicos, Franciscanos, Carmelitas Descalzos, monjas Carmelitas, Agustinas y de la Concepción, con cinco parroquias $^{\prime \prime 2}$. Pero, en fin, Juan Antonio Llorente, canónigo en Calahorra y viajero en ocasiones a la ciudad, no es precisamente un ejemplo de antiilustrado y menos de clérigo goyesco de misa y olla ${ }^{13}$. Con todo, aunque numeroso y rico -el clero de Logroño poseía el $30 \%$ de la tierra cultivable-, no parece que el principal estamento privilegiado de la ciudad fuera un fundamento de la circulación del libro a la luz de los resultados de nuestras pesquisas.

Más optimistas podríamos mostrarnos ante la presencia en Logroño de un impresor y dos libreros. La ciudad tuvo en el siglo XVI fábrica de papel y una magnífica imprenta ${ }^{14}$, en la que brilló Guillén de Brocar y, después, su yerno, Miguel de Eguía, pero por lo que sabemos en el XVII decayó y en el XVIII prácticamente no editaba más que cartillas, catecismos, impresos oficiales y bandos del ayuntamiento. "Desde que Miguel de Eguía no volviera a imprimir más que esporádicamente en su Estella natal, tras su asunto con la Inquisición, los molinos de los Soria (una familia de papeleros que tenía su fábrica en el Ebro), languidecieron sin remedio, aunque sin llegar a desaparecer" ${ }^{\prime \prime 15}$. Con todo, Logroño contaba a mediados del XVIII con una imprenta, aunque, como luego veremos, el impresor tampoco nos sorprenderá por las existencias de libros que tiene en sus anaqueles: en un inventario de 1760, Matías de San Martín tenía sólo 12 títulos de libros ${ }^{16}$.

10. Véase LAMARCA LANGA, G., La cultura del libro en la época de la llustración: Valencia 1740-1808. Valencia, 1994, p. 17 y ss.

11. Véase IBÁÑEZ RODRíGUEZ, S., El Pan de Dios y el pan de los Hombres. Diezmos, primicias y rentas en la diócesis de Calahorra (ss. XVI-XVIII). Logroño, 1999.

12. Jovellanos, Diarios, edición B.A.E. Cit. en ALONSO CASTROVIEJO, J. J., Logroño, $1751 \ldots, 1990$.

13. Véase sobre Llorente la excelente biografía que acaba de publicar FERNANDEZ PARDO, F., Juan Antonio Llorente: español maldito. San Sebastián, 2001.

14. Véase RAMÍREZ BAÑUELOS, J. M., "Las papelerías y la imprenta: dos historias paralelas" en GÓMEZ URDÁÑEZ, J. L. (coord.), Historia de la ciudad de logroño. Logroño, 1995, Tomo III, pp. 397-407.

15. Ibídem, pág. 398.

16. A.H.P. Lo., Caja 1.099, Libro 790. Véase apéndice 1. 


\section{Las luces... de algunos profesionales logroñeses}

Si para Genaro Lamarca "la generalidad de las bibliotecas valencianas de la segunda mitad del XVIII no puede ser catalogada, de ninguna manera, de abierta, innovadora, o mucho menos ilustrada" ${ }^{17}$, hay que suponer lo que nos espera en una ciudad como Logroño. En Valencia, donde el autor citado previene que hay "un panorama cultural muy rico" desde fines del XVII, había Universidad, un reconocido círculo de intelectuales liderado por el más importante del siglo, Gregorio Mayans, muchísimas más facilidades para la entrada de libros por su puerto y, en fin, una burguesía obviamente más "consumidora" de libros. En Logroño, ya hemos explicado lo que había: un colegio de los ignacianos, algunos maestros de escuela, muchos curas, y algunos profesionales que van a dar... la nota. Y sin embargo, Manuel de las Rivas se mostraba relativamente optimista hace unos años en el volumen III de La Historia de La Rioja. Al hablar de las bibliotecas ilustradas en La Rioja, reparaba en que burgueses y aristócratas tenían libros, por ejemplo de Rousseau y Voltaire, e incluso La Enciclopedia. El autor advierte que los datos proceden de fechas más tardías, en torno a 1820, pero supone con razón que la procedencia de muchos libros es seguramente de etapa anterior.

Manuel de Las Ribas nos daba también algún detalle de la biblioteca de una mujer, y además con el interés añadido de que los libros estaban firmados por ella, lo que nos evita, obviamente, la duda que ofrecen muchas veces los inventarios de viudas. Se trata evidentemente de una mujer de posibles, una Sáenz de Tejada, y los libros que tiene son los usuales de una biblioteca no profesional, culta. En ella encontramos tanto el Teatro crítico y Las cartas eruditas de Feijoo, como La justa repulsa del Padre Soto y Marne, el principal crítico de Feijoo, así como La Historia de España de Mariana, una edición de El Quijote y una edición del divulgado Semanario de Agricultura ${ }^{18}$. Aunque no la describe, Manuel de las Rivas menciona también la biblioteca de los Fernández de Navarrete, en Ábalos, que puede ser otro ejemplo de la actividad bibliófila de las minorías ${ }^{19}$.

Porque, en efecto, el libro es asunto minoritario en la ciudad de Logroño. En una buena parte de inventarios post mortem no encontramos libros, incluso cuando se trata de personajes de una cierta posición. Por ejemplo, no tienen libros don Nicolás José Bernabé de Bendigar y Arellano, Regidor Perpetuo, don José Ignacio de Salazar y Castejón, también Regidor Perpetuo, e incluso todo un Alcalde Mayor de Logroño y Abogado de los Reales Concejos, Manuel Navarro Navarrete, o un presbítero como Matías $\mathrm{Cruz}^{20}$. Obviamente el abogado y el clérigo debían tener libros, pero seguramente estarían en otro edificio, se habrí-

17. LAMARCA LANGA, G., La cultura..., pp. 196-197. La cursiva es nuestra.

18. Ver la colaboración de DE LAS RIBAS RAMÍREZ DE LA PISCINA. M., en GARCÍA PRADO, J. (coord.), Historia de La Rioja. Tomo III, pág. 178.

19. Sobre Fernández de Navarrete y el archivo y biblioteca de su casa en Ábalos, véase CÁSEDA TERESA, J. F., Martín Fernández de Navarrete y la literarura de su tiempo. Logroño, 1999.

20. Los inventarios de sus bienes, en A.H.P. Lo., Caja 1.094, Libro 769 y Caja 1.058, Libro 712. 
an repartido ya entre sus familiares, o fue un descuido del escribano, que no reparó en su importancia económica. En cualquier caso hay que hacer notar que en el inventario del abogado y alcalde mayor constaba que en su mesilla de noche había un rosario y un libro de oraciones titulado Ramillete de flores.

Contra estos inventarios excepcionales que nos inclinan a pensar en los conocidos problemas de la fuente, encontramos bibliotecas reducidas que no dejan lugar a dudas sobre la exigua bibliofilia del propietario. Así por ejemplo, la de María Rosa de las Heras, quien no tenía en su casa mas que un librito, uno de los más repetidos: la célebre Mística ciudad de Dios, de María de Ágreda, obra que aparece en muchas de las bibliotecas de la ciudad ${ }^{21}$. Otro caso es el de Domingo Pujano, que tenía sólo 2 tomos del Filosanctorum (sic) de Ribadeneyra ${ }^{22}$. En fin, hay otro inventario, el de los bienes de Javier de Echevarría realizado en 1798, en el que sólo se anotan dos títulos: una Crónica de Aragón impreso en Valencia en dos tomos y de nuevo la Mística ciudad de Dios, el best seller de los logroñeses del XVIII ${ }^{23}$. En general, cuando se trata de bibliotecas pequeñas, los libros suelen ser de devoción, aunque, como luego veremos, a veces hay bibliotecas profesionales de ciertas artes o ciencias que no necesitan muchos libros, como es el caso de la del escribano Pedro Sebastián Romero que sólo tiene 5 libros $^{24}$. Excepcionalmente, ocurre también que hay profesionales más reputados por su ciencia y que, al parecer, no la alimentan con libros, como es el caso del médico Jacinto Chavarría, cuyo inventario, fechado en 1773, se desvía de la norma y presenta sólo cinco libros de medicina y cirugía, entre ellos un manual contra la peste -enfermedad desconocida ya en el XVIIIy una "Cirugía universal, viejo"; sin embargo, el galeno posee un "manual de confesores", las obras en latín del padre Soto y una "Diferencia entre lo temporal y lo eterno". En total, todo un médico y sólo tiene 10 libros $^{25}$.

La ciudad contaba, como ya sabemos, con imprenta, pero tenía además una librería. Los dos establecimientos podrían inclinarnos al optimismo, pero las ilusiones se desvanecerán al comprobar los inventarios. Así, en la tienda, en 1718, entre garbanzos, pólvora, chocolate, camisas o alfileres, encontramos " 5 docenas y 1 libro" de Catón, a 11 reales la docena, y " 6 docenas de libros de Doctrina" a 3 reales la docena, además de resmas de papel y diferentes libros de los que el escribano no indica el título pero sí muy exactamente su precio: " 5 docenas de a 10 reales", "2 docenas y 9 libros de a 2,5 reales la docena" y "4 libros que costaron 26 reales" ${ }^{26}$.

21. G. Lamarca nos confirma en su estudio sobre Valencia que esta obra ocupaba el tercer lugar en los títilos piadosos más frecuentes. Cfr. LAMARCA, G., La cultura..., p. 115. El inventario de María Rosa de las Heras, A.H.P. Lo., Caja 1.044, Libro 684,.

22. A.H.P. Lo., Caja 1.045, Libro 689.

23. A.H.P. Lo., Caja 1.098, Libro 788, f. 36.

24. A.H.P. Lo., Caja 1.077, Libro 735.

25. A.H.P. Lo., Caja 1.090, Libro 762, f. 41.

26. A.H.P. Lo., Caja 970, Libro 564. 
El inventariado de los libros de la tienda recuerda algunos inventarios en los que el escribano anota sólo el número de volúmenes y a veces su precio. Tal es la estimación que se tiene por los libros. Sin embargo, en el caso de la imprenta, el inventario, realizado en 1760, nos permite conocer con más detalle los libros que tenía Matías de San Martín. Encontramos también "Catones" y "Doctrinas", 4 resmas del primero y 538 ejemplares del segundo, lo que demuestra algo ya conocido: se trata de los libros más vendidos, sin duda, en la ciudad de Logroño. Tras estos vienen, obviamente, los libros de piedad: libros de oraciones tipo Jardín florido, Vía Crucis, 550 libros de Novenas de San Vicente, 670 Vidas de Santa Catalina, y muchas estampas ${ }^{27}$.

Lo que vemos en la imprenta y en la librería es, en efecto, el mejor comprobante de lo que pasa en la ciudad. Los particulares tienen sobre todo libros de Santos, de devoción, de oraciones y, si amplían un poco su biblioteca, suelen hacerlo con El Quijote -el XVIII es el siglo del Quijote-, Quevedo, y desde luego Feijoo. Por ejemplo, José Ruiz de Palacio, seguramente clérigo, sólo tiene además de unos pocos libros de su profesión, El Quijote en dos tomos ${ }^{28}$.

Contra esta tónica tan pobre, algunos profesionales tienen bibliotecas bien surtidas al menos de libros de su profesión. Estamos seguros que de ampliar la cata realizada en el archivo, encontraríamos más bibliotecas, pero con las que tenemos ya podemos partir de un principio sólido: al menos una minoría de profesionales de Logroño está en buenas condiciones relativas en su profesión para el acceso a la información, lo que además va in crecendo durante el siglo. Sorprenden por su amplitud las bibliotecas de los arquitectos Mariategui y Aranguren, de las que hablaremos luego, pero también las de dos personajes, de los que no hemos podido conocer su profesión, don Pedro de Enderica y don Joaquín Bretón ${ }^{29}$.

El inventario de Enderica nos muestra una biblioteca muy variada pero tradicional, con Feijoo, Cervantes, Quevedo, como norte. Pero junto a muchas vidas de santos y libros de devoción, más o menos frecuentes, hay sorpresas como, por ejemplo, el memorial de Chumacero y Pimentel, las Cartas de Antonio Pérez, los Comentarios del marqués de San Felipe y varios libros de historia e incluso la obra de Zabala y Auñón, uno de los mejores proyectistas de la primera mitad del XVIII.

Igualmente variada es la biblioteca de Joaquín Bretón, inventariada en 1810, pero, en este caso, nos sorprenden los muchos libros de técnicas y ciencias aplicadas. Junto a una "Nueva práctica de criar caballos", aparecen una "cría de gallinas" y varios sobre el arte de la seda, el lino y, en general, la agricultura, incluyendo 16 tomos del Diccionario de Agricultura de Rocier. Sin duda, esta

27. Véase apéndice 1.

28. Véase apéndice 5.

29. Véase apéndices 6 y 7 , respectivamente. 
biblioteca ilustrada -acoge también un Eusebio, un Fray Gerundio "sin forro", Gacetas y Mercurios, un tomo de El Censor y otro de El Duende de Madridhabría sido inspirada por la parte más pragmática y técnica de la llustración. Las "actas de la Sociedad" es muy probable que fueran las de la Sociedad Económica de Amigos del País Riojano-Castellana.

Otro profesionales también están representados dignamente por sus bibliotecas. Por ejemplo, la del Coronel José Agustín tiene, entre sus 54 volúmenes, varias más o menos relacionadas con su profesión: 3 tomos de Reales Ordenanzas de 1762, una Política militar, una Historia de Méjico, un tomo de Milicias de 1764, etc. Pero, además, el militar tiene también 14 tomos con las obras de Feijoo, 2 Historias de Don Quijote, "dos tomos de Historia de España", y "7 libros pequeños en pasta y 9 libros pequeños de devoción". Por si tuviéramos alguna duda de la orientación que tuvieron las alianzas militares del siglo XVIII en España, el Coronel tiene un diccionario de francés ${ }^{30}$.

Pero donde más se nota la importancia del libro en la formación profesional es en el caso de dos arquitectos de los que hemos encontrado el inventario de sus bibliotecas. En la mejor tradición de la arquitectura española de la época, muy relacionada con la ingeniería, nuestros arquitectos Manuel de Mariategui y Francisco Alejo de Aranguren tienen una magnífica biblioteca de libros profesionales, especialmente el último, que en 1773 es calificado como "el de más acreditada conducta y habilidad de este país" ${ }^{\prime \prime 1}$.

De Mariategui apenas sabemos nada, salvo que testó el 23 de abril de $1761^{32}$. Su librería no es muy amplia, tiene 24 libros de su profesión y 8 de carácter religioso. Estos últimos son los habituales, entre ellos la inevitable La mística ciudad de Dios de Sor María de Ágreda. Entre los que tratan de su profesión, Mariategui está bien surtido, pero sólo de los clásicos; tiene la Arquitectura de Andrea Palladio, la de Sebastián Serlio, la de Vignola, la de Vitrubio, los 10 libros de arquitectura de Alberti, El tratado de arquitectura civil de Tosca y el de Manuel Losada, un tratadito este último impreso en Madrid en 1740. Salvo éste, y quizás algunos otros de los que no podemos conocer la fecha de edición, muchos de los libros de Mariategui son antiguos, ediciones del siglo XVI. Con todo, tiene una obra muy representativa y novedosa, como es El curso subterráneo de las aguas de Teodoro Ademans (1664-1726), ingeniero, culto ${ }^{33}$, cortesano, que escribió un tratado de construcción, una descripción de las minas de Almadén o este tratado de las aguas subterráneas. Desde luego, por Mariategui era difícil que pasara la "Arquitectura de la Razón".

30. Véase apéndice 2.

31. MARTÍNEZ GLERA, E., Arquitectura religiosa barroca en el valle del Iregua. Logroño, 1982, p. 223.

32. A.H.P. Lo., Caja 1.099, Libro 791, leg. 72- 73. Véase apéndice 3.

33. Su biblioteca en Madrid era excelente. Véase FERNÁNDEZ DURÁN, R., Gerónimo de Uztáriz, una política económica para Felipe V. Madrid, 1999, p. 373 y ss. 
Mucho más rica es la biblioteca de Francisco Alejo de Aranguren. El arquitecto fue muy valorado en su tiempo, quizás más como constructor de puentes, en lo que más trabajó ${ }^{34}$. El inventario que conocemos es de 17 de diciembre de $1785^{35}$, y se compone de un total de 89 obras. De ellas, 12 son de arquitectura, 8 son de matemáticas, 28 libros eclesiásticos, 10 sobre gramática y literatura, 10 de historia, geografía y temas de nobleza, 9 variados y 5 sin definición clara del título. La biblioteca tiene un componente técnico muy interesante, pues muestra a un arquitecto con interés por la matemática, lo que es frecuente en "el siglo de la medida". Feijoo había llamado ciencia forastera a la matemática, sin embargo, en la segunda mitad del siglo, las cosas habían mejorado mucho. Aranguren tiene el compendio en nueve tomos del valenciano Tomás Vicente Tosca, uno de los mejores divulgadores del XVIII, cuya obra se imprimió en Madrid y en Valencia; además posee libros de geometría, los elementos de Euclides, etc. Algunos de los libros de arquitectura de Aranguren están en italiano, lo que justificaría una "gramática" de esa lengua; junto a ella, figura una de la lengua castellana y el Diccionario de la Real Academia. Sin embargo, a las alturas de 1785 faltan obras muy importantes tanto en el campo del arte como de la técnica, lo que, al final, nos devuelve a la realidad, al quiero y no puedo como mucho. Pues en suma, la biblioteca profesional más amplia nos muestra también su... mucha edad.

\section{Para concluir}

Logroño muestra un comportamiento predecible en lo relativo a los libros, sin embargo y aún a sabiendas de que encontraremos pocas sorpresas, hay que proseguir la investigación en este campo. Precisamente porque sabemos que la Ilustración y la cultura libresca fueron cosas de minorías -"el vulgo tiene costumbre de hacer burla de los que escriben" ${ }^{36}$ - hemos de estudiar hasta qué punto llegó la minoría de la ciudad. Quizás descubramos que en las pequeñas ciudades castellanas ni siquiera se movilizó la minoría y que, al final, el Despotismo Ilustrado legó al siglo del liberalismo más despotismo que ilustración.

En cualquier caso, nuestras aportaciones son un elemento más para sumar al debate sobre la circulación de las ideas, el peso del libro en el acceso al saber y, en fin, la formación de una minoría culta y dirigente en un país atrasado, tal y como lo planteaba J. Sarrailh ${ }^{37}$. Al contrario, quizás lo que ocurre en los "países atrasados" es que ni siquiera es culta la minoría. En la ciudad de Logroño, así fue, en efecto, si la juzgamos por los libros que podía leer.

34. ARRÚE UGARTE, B. y MOYA VALGAÑóN, J. G., Catálogo de puentes anteriores a 1800 en La Rioja. Zaragoza, 1998.

35. Véase apéndice 4.

36. Cit. por Joseph PEREZ en la Introduction a "De la alphabetisation aux circuits du livre...", p. 5.

37. SARRAILH, J., La España Ilustrada de la segunda mitad del XVIII. Madrid, 1974 (1954). 


\section{Apéndice documental}

1. INVENTARIO DE LOS BIENES QUE QUEDARON A LA MUERTE DE DON MATIAS DE SAN MARTIN, IMPRESOR DE LA IMPRENTA DE LOGROÑO. 4 DE AGOSTO DE 1760.

A.H.P. Lo., Caja 1.099, Libro790.

(...)

Libros (...) quatro resmas de libros de Catón en ciento y Veinte reales, 120

quinientos y treinta y ocho libros de la Doctrina en noventa reales, 90

una resma de libros del Reino, 30

una resma de libros de Jardín florido, catorce romances y vía crucis, 30

quinientos y cincuenta libros de novenas de San Vicente en 66

dos resmas de romances en 60

seis manos de estampas de nuestra Señora de Balbanera en 13

otras cinco manos de estas estampas, 12

unas Platiquilla, 6

tres libros de San Joaquin, 20

seiscientas y setenta Vidas de Santa Catalina que se han de partir entre los qua-

tro herederos (...)

un libro de desengaños del mundo, 1

veinte y cinco quadernillos impresos para libros, 16

(...)

2. INVENTARIO DE LOS BIENES QUE QUEDARON A LA MUERTE DE DON JOSEF AGUSTIN, CORONEL DEL REGIMIENTO DE MILICIAS

DE LOGROÑO. 3 DE NOVIEMBRE DE 1770.

A.H.P. Lo., Caja 1.077, Libro 735.

(...)

Catorce thomos de libros en quarto, obras de Feijoo.

Otro de folio de Historia de México.

Otro impresa política militar.

Otro de los señores Barca y Rota.

Otro expediente de el Obispo de Cuenca.

Tres thomos de reales ordenanzas de el año de sesenta y dos.

Un thomo de milicias de el año sesenta y cuatro.

Otros vales de vida debota.

Tres thomos diccionario geografico.

Otras dos memorias de las Reinas Católicas.

Un thomo literaria de España.

Dos historias de Don Quijote.

Tres historias literarias de España.

Dos thomos historia de España 
Otro diccionario de lengua española y francesa.

Siete libros pequeños en pasta.

Nuebe libros pequeños de deboción.

3. INVENTARIO DE LOS BIENES DE MANUEL DE MARIATEGUI (arquitecto). Logroño 23 de Abril de 1761.

A.H.P. Lo., Caja 1.099, Libro 791.

(...)

Item un estante con su celosía con los libros siguientes:

Dos tomos en folio que contiene las obras de Moya.

Un tomo en folio los quatro libros de arquitectura de Andrea Paladio.

Un tomo en folio tercero y quarto de arquitectura de Sebastián Serlio.

Otro de folio de idea de arquitectura universal de Vicencio Escamozi.

Otro de folio de los diez libros de arquitectura de Vitrubio.

Otro de segunda parte de arquitectura de Fray Lorenzo de S. Nicolás.

Otro tomo de pasta de arquitectura de novelas de Venecia.

Otro en folio los cinco órdenes de arquitectura de Biñola.

Otro en folio de arquitectura de Juan Jorifa.

Otro en folio de antigüedades de Roma.

Otro en folio de arquitectura de Plantas y Alzados de Casas y Palacios.

Otro en folio Maquinaria de Francisco Beroaldi.

Otro en folio Perspectiva de autor.

Otro en quatro de Fluencias de la tierra curso subterráneo de las aguas de D.

Theodoro Ardemans.

Otro de Ordenanzas del mismo autor.

Otro los diez libros de Leon Bautista Alberto.

Otro de arquitectura civil de Manuel Losada.

Otro las ordenanzas de Toriga.

Otro en quarto Mística Ciudad de Dios.

Otro Consejos de la Sabiduría de Salomón.

Tres tomos de David perseguido.

Otro exequias del Cardenal Molina.

Otro quinto tomo de arquitectura de Tosca en octavo.

Otro de arquitectura de antigüedades de Roma.

Otro en quatro arquitectura de Berruguilla.

Otro en octavo escudo del Carmelo.

Otro en octavo de Mesías de Jesús.

Otro en octavo Policía de la Ciudad de Logroño.

Otro en octavo Privilegio de la Unión de la Ciudad de Pamplona.

Otro en octavo el devoto peregrino.

Otro en pasta meditación de Cristo.

Otro en pasta Viñola de arquitectura.

(...) 


\section{INVENTARIO DE LOS BIENES DE DON FRANCISCO ALEJO DE ARANGU- REN, ARQUITECTO. LOGROÑO 1785.}

A.H.P. Lo., Caja 1.116, Libro 817.

En Logroño a diez y siete de Diciembre de mil setecientos ochenta y cinco su señora con mi asistencia y la de los demas interesados probidencia es de continuar este inbentario y tasación en la forma siguiente...

Lo primero Miguel Armas (...) tasa la obra intitulada elementos de Matematicas por Don Benito Bailes que comprende los tomos primero, segundo, tercero, cuarto, quinto, sexto y noveno en trescientos y treinta reales.

Otro libro intitulado Simson Elementos de Euclides en quarto maior y pasta en treinta reales.

Otro libro titulado Canals colección de la (....) un tomo en quarto maior y pasta encarnada cincuenta reales.

Otro libro en quarto y pergamino intitulado Gramatica Italiana Porthomar en diez reales.

Otro en octabo y pergamino titulado Gramatica Castellana por la Real Academia seis reales.

Tres tomos en octabo maior y pasta de principios de Matematicas por Don Benito Bailes ochenta reales.

Cinco tomos en quarto y pasta titulados: obras en Prosa y Verso de Don Diego Antonio Cornadas en a doce reales cada uno por faltar los tomos tercero y cuarto y siempre que se berifique encontrarse y completamente la obra tasó toda ella a diez y ocho reales cada tomo.

Otro tomo en quarto y pasta titulado El Sacrosanto Concilio de Trento en latín y castellano en veinte y cuatro reales.

Dos tomos el uno titulado Atlas Celeste. Impresión de Paris en pasta y quarto en treinta reales y el otro en quarto algo maior titulado Atlas Terrestres en treinta y seis reales.

Dos tomos en dorado y pasta titulado (...) discursos sobre la Historia Universal en lengua francesa en doce reales.

(...) compendio de la Historia de España.

Dos tomos (...) Bolumen de octabo (...) y pasta en doce reales.

Vignola Regla de las cinco Ordenes de Arquitectura un tomo en folio y pergamino en diez y seis reales.

(...) tratado de todo genero de bóbedas un tomo en folio y pergamino en doce reales.

Medrano (...) un tomo en folio y pergamino en diez y seis reales.

Croiset año Cristiano doce tomos en quarto y pasta ciento y sesenta reales.

Item Dominicos de todo el año seis tomos en quarto y pasta en ochenta reales.

Espinosa Indice general del año Cristiano un tomo en quarto y pasta en doce reales.

Saabedra Republica literaria un tomo en octabo y pergamino en cuatro reales. 
Cervantes novelas ejemplares dos tomos en octabo maior y pasta en treinta y seis reales.

Item Vida y hechos de Don Quijote de la Mancha en cuatro tomos en octabo maior y pasta en cincuenta reales.

Rebolledo (Don Bernardino) una obra en cuatro tomos en octabo maior y pasta en cincuenta reales.

Fleury, Catecismo Historico de la Religion. Dos tomos en octabo y pasta en doce reales.

Nipho, La Labranza Española. Siete tomos en octabo y pasta en cincuenta reales.

Ibañez, Compendio del año Cristiano doce tomos en octabo y pasta en noventa reales.

(Mendo) Dominica del año (...) a la obra del Compendio del Año cristiano en seis tomos en octabo y pasta en cuarenta y dos reales.

(...) Escuela de Corazon dos tomos en octabo y pasta en diez y seis reales.

Tablas cronológicas de la sucesion pontificia y Real de España, un tomo en octabo y pasta en cuatro reales.

Escribano, Guia de Caminos un tomo en octabo y pasta en tres reales.

Viñola, Las Cinco ordenes de Arquitectura en un tomo en folio maior y pasta en ochenta reales.

Neuforge, Reglas de Arquitectura un tomo en folio maior y pasta nobenta reales.

Item como el anterior en nobenta reales.

Item Otro del mismo autor que trata de la Materia nobenta reales.

Vitruvio de Arquitectura en un tomo folio maior y pasta en italiano en cien reales.

Item de Arquitectura en lengua castellana un tomo en folio y pasta en cincuenta reales.

Diccionario de la Lengua Castellana compuesto por la Real Academia un tomo en folio maior y pasta en nobenta reales.

Fontana, Traslacion del paradime obelisco del baticano un tomo en folio maior y pergamino en sesenta reales.

Paladio de Arquitectura en italiano y frances un tomo en folio y pergamino en cuarenta y cinco reales.

(...) Conmemoracion para la escolastica un tomo en folio y pergamino en cuarenta reales.

Fray Lorenzo de San Nicolas, Arte(...) de Arquitectura el tomo segundo en folio y pergamino diez reales.

Vitruvio, compendio de Arquitectura un tomo en Octabo Maior y pergamino en ocho reales.

Tosca, Compendio de Matematica nueve tomos en Octabo Maior y pasta en ciento y cincuenta reales. 
Lampillan, Literatura Española Seis tomos en quarto y pergamino en sesenta reales.

Tres tomos en quarto y pergamino de Arquitectura Mano escrita en quarto y pergamino en seis reales (...)

Otro tambien Mano escrito de Aritmetica en ocho reales.

(...) Sucesos Memorables del Mundo cuatro thomos en octabo y pasta en veinte reales.

Echeberría, Geometría práctica un tomo en octabo y pasta en cuatro reales.

Baron, (...) de la fe y de la ley un tomo en folio y pergamino en diez y ocho reales.

Aranda, vida del Cardenal Espínola un tomo en folio y pergamino en diez reales.

Ribadeneira fios sextorum tres pares de bolumenes de folio y pergamino maltratados en veinte reales.

Vega vida del Beato Simon de (...) en un tomo en folio y pergamino diez reales.

Ceballos, vida de San Antonio Abad un tomo en cuarto en pergamino en quatro reales.

Arus, Semanario Economico cuatro tomos (los tres) en pergamino y el quarto en pasta en cuarenta reales.

Morzo, ensaios para las ciencias el tomo primero en quarto y pergamino en diez reales.

(Etenar), destreza de las Armas un tomo en quarto y pergamino en ocho reales.

Trincado, Compendio de los Soberanos de Europa un tomo en quarto y pergamino ocho reales.

(Moia), Armas y Blasones de España un tomo en quarto y pergamino en ocho reales.

Agricultura del (Príor) un tomo en quarto y pergamino en siete reales.

Salamó, Regla de vida un tomo en octabo y pasta seis reales.

Plo, el Arquitecto práctico un tomo en octabo y pasta quince reales.

Castro, Uso del Compas un tomo en octabo y pergamino diez reales.

Villarroel, Historia Sagrada el tomo primero en quarto y pergamino en tres reales.

El Dorado Contado un tomo en quarto y pergamino tres reales.

Rodriguez, Sobre el bien del estado religioso un tomo en octabo maior y pergamino en cuatro reales.

Euclides, Tratados un tomo en octabo maior y pergamino en cuatro reales.

(...) España doce tomos en octabo maior y pasta en ciento y veinte reales.

Florez, tratado de las Medallas de España dos thomos en quarto maior y pasta en ochenta reales.

Jimenez, Descripción del Escorial en un tomo en folio y pasta treinta y seis reales.

Sánchez, tratado de fortificación dos tomos en quarto y pasta en sesenta reales. 
Lucuze, Disertación sobre las medidas (...) un tomo en quarto y pasta en doce reales.

Vubard, proiecto economico un tomo en quarto y pasta en diez y seis reales.

Viñola, Las Cinco ordenes de Arquitectura un tomo en octabo Maior en pasta en veínte y cuatro reales.

Ardemans, ordenanzas de Madrid un tomo en quarto y pasta en doce reales.

Florez, Clabe Historial un tomo en quarto y pasta en veínte reales.

Suarez, Colección General de Maquinas un tomo duplicado en quarto y pergamino quarenta reales.

Duquesne, Compendio de la Historia de España dos tomos en octabo y pasta díez y seis reales.

Fuente, Sucesión Real despaña tres tomos en octabo y pasta en veínte y dos reales.

Castellot, Semana Santa en lengua castellana un tomo en dorado y pasta en doce reales.

Miguel, Semana Santa un tomo en octabo y pasta en diez reales.

Florez, Clabe Geografica un tomo en octabo y pasta en ocho reales.

Ribadeneira, Soliloquios y meditaciones de San Agustín dos tomos en octabo y pasta en quince reales.

(Axfil) Alma de San Aguntin sacada de sus confesiones un tomo en octabo en dos reales.

Reino espiritual del Padre Altamirano un tomo en octabo y pergamino en cinco reales.

Formulario de Cartas un tomo en octabo y pergamino en cuatro reales.

Menand Un tomo en folio Maior que trata del Cuerpo de las Piedras con barias Laminas en treinta reales.

Un quaderno de Mapas para arquitectos en quarto Maior y forro de papel en ocho reales.

Granada, Oración y Meditación un tomo en octabo y pasta seis reales.

Valero, Carta Pastoral un tomo en octabo y pasta en seis reales.

Barreda, El Año de la Nobleza un tomo en octabo y pergamino en cinco reales. Kempis, Meditación de Cristo, un tomo en octabo y pasta en cinco reales.

Pouget, Instrucciones Generales en forma de Catecismo quatro thomos en octabo Maior y Pasta en sesenta reales.

I en este estado por ser la tarde y haberse concluido la tasación de libros se suspendió esta Diligencia (...)

5. INVENTARIO DE LOS BIENES DE JOSÉ RUIZ DE PALACIOS.

A.H.P. Lo., Caja 1.085, folio 55.

(...)

- 5 tomos en cuartilla de las Madre Jesús de Ágreda.

- 2 tomos en cuartilla de Don quijote

- 4 tomos en cuartilla de David perseguido y penitente 
- 1 tomo en cuartilla de Molina de sacerdotes

- 1 tomo de La diferencia entre lo temporal y lo eterno

- 1 tomo intitulado Guía de pecadores

- 1 directorio moral en cuartilla

- 1 tomo en cuartilla que se intitula Gabanto de ceremonias

- La vida interior del venerable Palafox en cuartillas

- En cuartillas del P. Fuentes

- En cuartilla intitulado de Venganza mística

- 2 tomos en cuartilla de cartas pastorales del señor Moltalván y Valero

- 2 tomos en cuartilla de la Suma del Pacheco Viejo

- 1 Suma de Corella en cuartilla

- 1 Suma de Riquet en cuartilla

- 2 Breviarios

- 2 tomos que se intitulan Crisol de desengaños

\section{INVENTARIO DE BIENES DE DON PEDRO ENDERICA.}

\section{A.H.P. Lo., Caja 1.151, folio 57}

(...)

- 4 tomos de Nepueu (?) pensamientos o reflexiones cristianas, para todos los días del año, en castellano y pergamino.

- Catecismo práctico del Padre Calatayud. Un tomo viejo y en pergamino.

- Estilo de cartas de don Gaspar de Ezpeleta. Un tomo en pasta.

- Estragos de la lujuria y sus remedios del Padre Arbiol. Un tomo en pergamino.

- El Atlas abreviado del mundo antiguo y nuevo con láminas, en pasta. Su autor Don Francisco Alfordem.

- Historia de Nuestra Señora de Valvanera. En pasta un tomo de cuartilla.

- Compendio de la Historia de España, traducido al castellano por el Padre Isla. Dos tomos en pasta.

- Vida de San Estanislao de Korca en pasta, otro de la vida.

- Mística ciudad de Dios de la Venerable María de Jesús de Ágreda en ocho tomos en octavo y en pasta y separado también en pasta otro de la vida de la venerable Madre.

- Sales: Vida devota, un tomo en pasta.

- Teatro crítico del Padre Maestro Feijoo, en nueve tomos con el suplemento y otros cinco de cartas eruditas con la Ilustración Apologética al primero y segundo tomo contra Mañer y la injusta repulsa de inicuas acusaciones contra Sotomarne, todos en pergamino. Demostración del teatro crítico del Padre Maestro Sarmiento, dos tomos en pergamino.

- Tres tomos en cuarto y en pergamino de don Salvador Jose Mañer, los dos antiteatros crítico sobre el primero y el segundo tomo de Feijoo y el otro réplica satisfactoria a la Ilustración Apologética de Feijoo 
- Otros tres tomos en pergamino y en cuarto del teatro anticrítico, sobre las obras de los Maestros Feijoo y Sarmiento y de Mañer, escritos por don Ignacio de Armesto Osorio

- Don Quijote, dos tomos en pergamino

- La monja de México: obras poéticas. Dos tomos en pergamino

- La Galatea y Viaje al Parnaso de Cervantes. Un tomo en pergamino

- Comentarios del Marqués de San Felipe. Dos tomos en pergamino

- Vida de San Antonio Abad. Un tomo en pergamino

- Vida de San Ignacio de Loyola. Un tomo en pergamino

- Cartas de Santa Teresa de Jesús. Dos tomos en pergamino

- Aritmética de Moia. Otro tomo en pergamino

- Vida de San Luis Gonzaga. Un tomo en pasta

- Arbiol: Visita de enfermos. Un tomo en pasta

- Quevedo. Un tomo en pasta

- Diferencia de Eusebio. Dos tomos en pasta

- Solís: Conquista de México. Un tomo sea folio en pergamino

- Carlos V: su historia. Un tomo sea folio en pergamino muy viejo con falta de algunas hojas

- Guerras civiles de Tracia, de Enrico Catarino. Un tomo sea folio viejo, se puso en pasta

- El contador lego. Sea folio en pergamino

- Curia filípica. Un tomo sea folio en pergamino

- Miscelánea económico política o discursos varios sobre el modo de aliviar los vasallos con aumento del Real Herario. Su autor Zabala. Un tomo sea folio

- Comentarios de Gaio Julio Cesar de la guerra de Francia. Un tomo en pergamino

- Cartas de Antonio Pérez. Un tomo en pergamino

- Memorial de Chumacero y don Francisco Domingo Pimentel obispo de Córdoba a Urbano VIII. Un tomo en pergamino

- Autos sacramentales de Calderón. Un tomo

- Resumen de la destreza de las armas de don Miguel Pérez de Mendoza y Quijada. Un tomo en pergamino

- Obras de don Juan de Zabaleta. Un tomo en pergamino

- Práctica de testamentos y modos de suceder. Un tomo en pergamino muy viejo y sin principio

- David arrepentido. Un tomo otras dos partes segunda y tercera de David perseguido, en pergamino

- Cartilla de escribanos real. Tres tomos pequeños en pergamino

- Aventuras del B. Trapaza. Un tomo en pergamino

- Silva de varia lección. Otro tomo en pergamino que está sin principio

- Vida y purgatorio de San Patricio. Un tomo viejo. 
7. INVENTARIO DE BIENES DE JOAQUÍN BRETÓN. 1810.

A.H.P. Lo., Caja 1.143, Libro 858, folio 128

(...)

- Un mapa de Europa, otro de España, otro de Alemania y dos de Gibraltar

- 11 tomos en cuarto forrados en pergamino, colección de Gacetas

- Otro en pasta, en cuarto, titulado Prontuario de varias órdenes reales

- Otro titulado Quien complace a la Deidad acierta a sacrificar

- Dos en cuarto y en pasta, titulado Tertulia de la aldea

- Otro en pasta titulado Persiles y Segismunda

- 16 tomos en cuarto y en pasta titulado Diccionario de agricultura de Rocier

- Otro en cuarto y en forro de pergamino, titulado Nueva práctica de criar caballos

- Otro tomo en cuarto del Tratado de agricultura

- 4 tomos sin forro de la Historia de fray Gerundio

- 4 tomos del Teatro crítico de Feijoo

- Otro sobre la Cría de gallinas

- Otro El duende de Madrid

- Otro Método de blanquear el lino

- Otro Actas de la sociedad

- Otro de caminos y cortejos

- 41 tomos en octavo, colección de varios Mercurios

- Diferentes guías de forasteros antiguas

- 2 tomos de Oficio de cicerón

- Primer tomo del Eusebio

- Otro de política

- Otro tomo en octavo, Tradicción del himnos

- Ordenanzas de esta ciudad

- Otro del café

- Otro sobre el cultivo de morera

- Otro Estado de la Real Hacienda

- Otro Familia regular

- Otro El hombre justo

- 3 tomos de folio de Mística ciudad de Dios

- En pergamino Signodales de Calahorra

- Establecimiento de la Orden de Santiago

- En pasta y en octavo 2 tomos de la Historia del Perú

- Seis tomos del Quijote

- Pleito entre dos casados

- La cría de gallinas

- La seda

- Una Semana Santa en castellano y otra en latín

- El oficio pasivo

- El de difuntos 
- Los Hechos de los Apóstoles en castellano

- Elogio del rey de Prusia

- Gobierno del hombre de negocios

- Tesoro escondido en la viña

- 2 tomos de Los enredos de un lugar

- 2 tomos de Tertulia de la aldea

- 4 tomos de Conocimiento de Jesucristo

- 1 tomo de Poesía de Aldana

- 1 tomo del Censor

- 5 tomos del Compendio de la Historia de España, todos en pasta

- 1 Atlas abreviado

8. INVENTARIO DE BIENES DEL SEÑOR D. JOSEPH FERNANDEZ DEL AGUILA, NOTARIO RECEPTOR DEL TRIBUNAL ECLESIASTICO DEL OBISPADO DE CALAHORRA Y LA CALZADA, FALLECIDO EN QUEL. 1752.

A.H.P. Lo., Caja 1.066, Libro 722.

(...)

- Parte III del Grande Hijo de David

- Vida del padre Ávila, por Luis de Granada

- Padre Hoyos, por el padre Manuel de Prado

- Práctica de rentas reales

- Doctrina Cristiana

- Ejercicios de San Ignacio de Loyola

- Vida cristiana o práctica fácil de entablarla, por el padre Gerardo Armenti

- Meditaciones, por el padre Puente

- Manual y ejercicios cristianos de cada día, recopilado por Tomás López de Haro

- Soliloquios divinos, por Mariano Villegas 